\title{
The Development of Innovative Handheld Devices to Augment Cardiopulmonary Resuscitation Therapy and External Cardioversion and Defibrillation
}

\author{
MELANIE L. GERSHMAN ${ }^{1}$, BRANDON S. NEEDELMAN, BS ${ }^{1}$, SAM N. SCHWARZWALD, BS $^{1}$ \\ and TODD J. COHEN, MD ${ }^{1}$
}

${ }^{1}$ NYU Winthrop Hospital, Mineola, NY, USA

\begin{abstract}
Active compression-decompression (ACD) cardiopulmonary resuscitation (CPR) devices were conceived and invented by Drs. Todd Cohen and Keith Lurie to improve the low survival rates for conventional CPR. Active decompression creates greater chest recoil as compared with the passive decompression used in standard CPR, leading to increased preload and greater cardiac output. ACD CPR devices use a suction cup to adhere themselves to the patient's chest. Putting downward force onto the device allows for the operator to actively compress the chest. Active chest decompression is achieved by pulling up on the device (using its suction), which in turn pulls up on the patient's chest, enabling greater chest expansion. Animal and human studies have demonstrated an improvement in overall circulation when using ACD CPR versus standard CPR. The impedance threshold device (ITD) was created to enhance ACD CPR. This device connects to the patient's airway and prevents the influx of air during chest decompression. $A C D C P R$ plus ITD improves myocardial and cerebral perfusion, increases survival rates, and is associated with more favorable neurological outcomes. CPR guidelines permit the use of the above two devices by properly trained personnel. Additionally, an insulated handheld compression device can be actively applied over a standard defibrillation patch to decrease transthoracic impedance. This methodology has been incorporated into a patented PrestoPush ${ }^{\mathrm{TM}}$ device (Nexus Control Systems LLC, Port Washington, NY, USA), which is a handheld external cardioversion/defibrillation augmenter. This paper reviews the development of these innovative devices to augment standard CPR and external cardioversion and defibrillation, including summaries of studies the authors consider to those that are most significant in ACD CPR development.
\end{abstract}

KEYWORDS. Active compression-decompression, cardiopulmonary resuscitation, cardioversion, defibrillation, impedance threshold device.
ISSN 2156-3977 (print) ISSN 2156-3993 (online) CC BY 4.0 license

(C) 2017 Innovations in Cardiac Rhythm Management

\footnotetext{
Dr. Cohen is a co-inventor of the active compression-decompression device mentioned in this publication and is listed on related US patents belonging to the University of California. Dr. Cohen receives royalties through the University of California for this invention. In addition, his company, Nexus Control Systems LLC, owns the rights to the patents related to PrestoPatch ${ }^{\mathrm{TM}}$ and PrestoPush ${ }^{\mathrm{TM}}$. He is a co-inventor on each of these patents as well. The other authors report no conflicts of interest for the published content.

Manuscript received September 5, 2017. Final version accepted September 26, 2017.

Address correspondence to: Todd J. Cohen, MD, NYU Winthrop Hospital, 212 Jericho Tpke, Mineola, NY 11501, USA.

E-mail: tcohen@nyuwinthrop.org.
}

\section{Introduction}

Handheld devices have been developed to augment cardiopulmonary resuscitation (CPR), as well as to improve the efficacy of external cardioversion and defibrillation. This paper describes these innovations, their literature, and recommendations in usage.

\section{Background}

According to the American Heart Association (AHA), over 550,000 people experienced a cardiac arrest in the United 
States in 2016, with survival rates of $12 \%$ and $24.8 \%$ for outof-hospital and in-hospital episodes, respectively. ${ }^{1}$ Since the AHA first endorsed CPR in the 1960s, there have been few updates to the protocol until the last two decades. ${ }^{2}$ In a letter to the editor of the Journal of the American Medical Association, Dr. Keith Lurie described a 1985 case in which a toilet plunger was used to aid in the resuscitation of a 65-year-old man with coronary artery disease after traditional CPR failed. It was hypothesized that the plunger provided both active compression and decompression of the chest, and may have assisted with ventilation. ${ }^{3}$ This led Dr. Lurie and Dr. Todd Cohen to create an active compression-decompression (ACD) CPR device.

\section{The unmet need}

There is a need to update standard cardiac arrest CPR methods due to the low survival rate associated with this technique. The goal is to create a device that will augment circulation, increase CPR effectiveness, and improve survival. No specifically designed cardioversion/defibrillation devices exist to control the force applied over an external skin patch to reduce transthoracic impedance and improve procedural efficacy; the proposed device was also designed to fill this void.

\section{$A C D$ CPR concept}

During standard CPR, there is active chest compression where the resuscitator pushes down on the patient's chest, and passive chest compression as the chest recoils, respectively. In ACD CPR, the decompression becomes active, and the device sucks up on the chest. This provides more pronounced recoil, leading to greater negative pressure within the thorax to enhance cardiopulmonary circulation. ${ }^{4,5}$

Greater chest recoil draws more blood back into the heart, increasing the preload and cardiac output. ${ }^{6}$ The ACD CPR device can also provide deeper and faster chest compressions than its traditional counterpart, which have been associated with improved survival following cardiac arrest. ${ }^{7}$

The handheld ACD CPR device is comprised of a suction cup, handle, and force gauge. ${ }^{6}$ The suction cup is placed on the individual's chest, where it functions much like a plunger, pulling up on the chest to create active decompression. A compression pad lines the suction cup, acting like a cushion. The handle allows for a transfer of force from the rescuer to the distressed individual. ${ }^{5}$ The gauge on the top of the pump shows the forces applied during compression and decompression, while the audible metronome guides the proper compression rate. ${ }^{6}$ This device requires minimal training and causes less operator fatigue than traditional CPR. ${ }^{8}$

Figure 1 demonstrates the three versions of the device and how it was developed. Figure 1A shows the first device used in human trials, manufactured by AMBU Inc. (Copenhagen, Denmark). Figure 1B depicts the CardioPump $^{\circledR}$ (AMBU Inc., Copenhagen, Denmark), a lighter and more colorful commercial design that includes a crash cart strap, a more ergonomic handle, a built-in metronome, and embossed instructions for use. This model was used in the first multicenter trial in the early 1990s. Figure 1C is the current device, the ResQPump ${ }^{\circledR}$ (Zoll Medical Corp., Chelmsford, MA, USA), which is

A

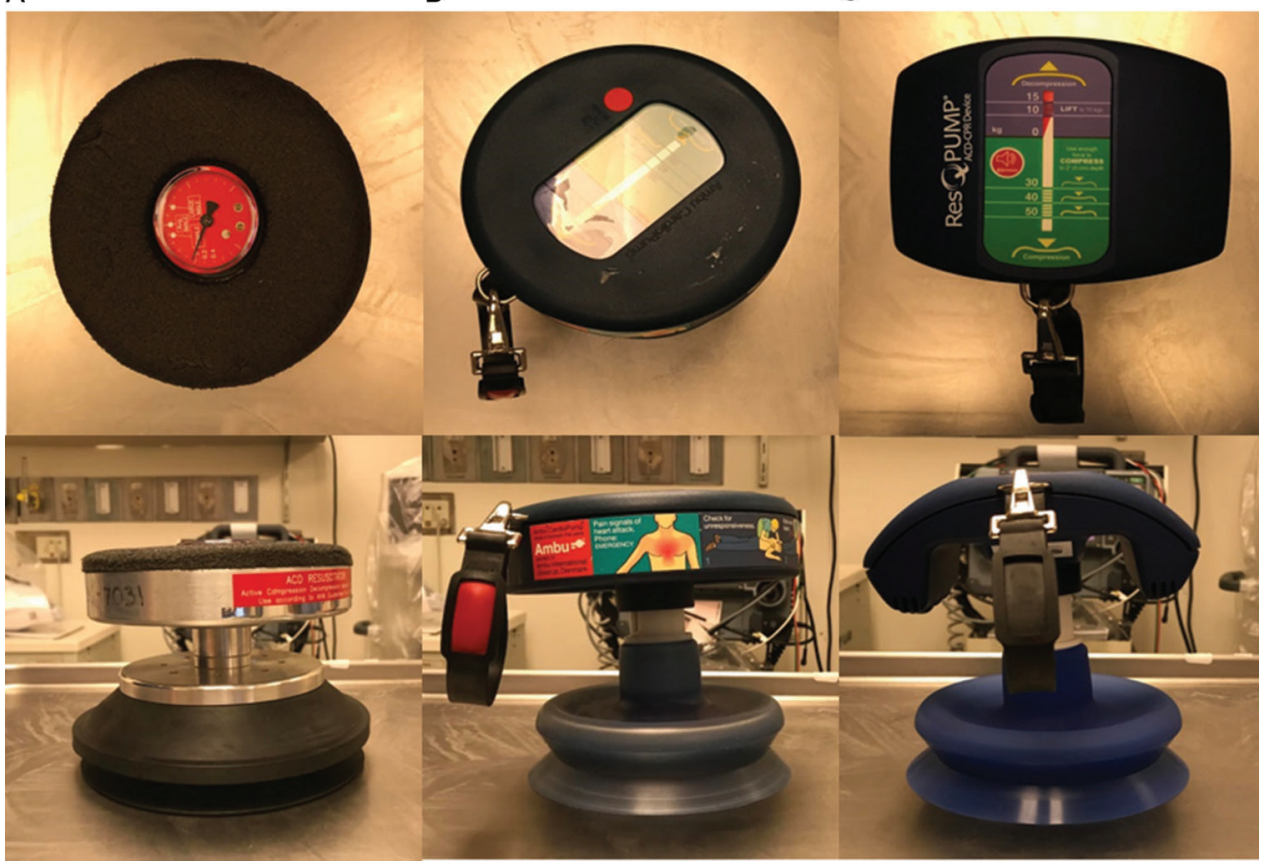

Figure 1: A: The first ACD CPR device used in human trials, manufactured by AMBU Inc. (Copenhagen, Denmark). B: The ACD CPR device known as the CardioPump ${ }^{\mathbb{R}}$ (AMBU Inc., Copenhagen, Denmark). C: The ACD CPR device known as the ResQPump ${ }^{\mathbb{R}}$ (Zoll Medical Corp., Chelmsford, MA, USA). 
approved for use by the US Food and Drug Administration (FDA).

\section{Trials}

\section{Early feasibility}

A canine study was published in 1992 by Cohen et al. to compare the efficacies of standard CPR and ACD CPR using a simple handheld suction device planted on the middle of the sternum. After inducing ventricular fibrillation, the eight non-ventilated anesthetized dogs were randomized to receive ACD CPR and standard CPR sequentially, with each technique conducted under the same parameters but in different orders. Transesophageal pulsed wave Doppler echocardiography from the main pulmonary artery revealed that ACD CPR demonstrated significantly improved coronary perfusion pressure, cardiac output, minute ventilation, and systolic arterial pressure as compared with standard CPR. ${ }^{9}$

Later that year, a study conducted by Lindner et al. investigated the effects of ACD CPR and standard CPR on myocardial and cerebral blood flow in pigs. After inducing ventricular fibrillation, 14 pigs were randomized to receive either ACD CPR or standard CPR under the same parameters for five minutes. Following this interval, radiolabeled microspheres were injected into the pigs and showed that ACD CPR yielded a significantly higher median cerebral blood flow and improved aortic, systolic, and diastolic pressures. It also improved coronary systolic and diastolic perfusion pressures, endtidal carbon dioxide $\left(\mathrm{CO}_{2}\right)$, cerebral oxygen delivery, and cerebral perfusion pressure to greater extents than did standard CPR. ${ }^{10}$

\section{Human studies}

In 1992, Cohen et al. published the first human study that examined the efficacy of ACD CPR using the device shown in Figure 1A. Ten patients were randomized to be given two minutes of either standard CPR or ACD CPR, followed by two minutes of the other technique. The authors reported significant increases in blood circulation, end-tidal $\mathrm{CO}_{2}$ concentration, and systolic arterial pressure associated with $\mathrm{ACD} C P R$ use in comparison with traditional CPR. Furthermore, the improved systolic arterial pressure correlated with increased cerebral perfusion. The authors concluded that cardiovascular, pulmonary, and systemic hemodynamics improved significantly with the use of ACD CPR as opposed to standard CPR. ${ }^{8}$

A 1993 study by Tucker et al. compared transmitral flow and left ventricular volume between ACD CPR and standard CPR. ${ }^{11}$ Five patients were randomized using a methodology similar to that employed by Cohen et al. ${ }^{7}$ Data collected by transesophageal echocardiography revealed that ACD CPR led to increased transmitral flow, end-decompensation left ventricular volume, and stroke volume to greater degrees than did conventional
CPR. Unfortunately, no cardiac arrest patient in either group survived. ${ }^{11}$

In a 1993 study published in The New England Journal of Medicine, Cohen et al. compared the short-term outcomes of ACD CPR and standard CPR with respect to inhospital cardiac arrest management. Sixty-two patients who experienced witnessed cardiac arrest were randomly assigned to receive either ACD CPR or standard CPR under identical conditions. This study was terminated by the FDA prior to completion but demonstrated that ACD CPR led to significantly higher initial resuscitation and 24-h survival rates, as well as better neurologic outcomes. Two patients who received ACD CPR survived to hospital discharge, while no patient receiving standard CPR lived to this endpoint. ${ }^{12}$ ACD CPR also increased survival to intensive care unit admission in a 1994 study by Shultz et al., with an increase in favorable neurological outcomes in patients who received ACD $\mathrm{CPR}$ as compared with patients who received standard CPR. ${ }^{13}$ In 2016, Gunaydin et al. studied 181 patients who were randomly assigned to receive either standard or ACD CPR. They found no significant differences in survival or discharge rates; however, standard CPR had a higher complication rate, including a higher incidence of rib fractures. ${ }^{5}$

\section{Flaws with using ACD CPR alone}

Multiple studies reported no significant increase in patient survival with ACD CPR in comparison with traditional CPR. In 1999, Maur et al. performed a combined analysis to evaluate the effects of standard and ACD CPR. They found greater rates of one-hour survival with ACD CPR use but no significant difference in survival to discharge. ${ }^{14}$ Notably, one of the included studies used medical personnel who had worked with the ACD CPR device for more than one year, ${ }_{15}^{15}$ while practitioners in other investigations had used ACD CPR for only a few weeks prior to the commencement of the respective studies. ${ }^{4}$ Plaisance et al. reported improved survival rates with ACD CPR versus standard CPR techniques, suggesting that familiarity with the ACD CPR device is a possible contributor to increased patient survival rate.,

A 2013 meta-analysis by Luo et al. analyzed a total of 13 studies and found improved restoration of spontaneous circulation (ROSC) and increased 24-hour survival for ACD CPR versus standard CPR; however, there were no significant differences in survival rates to hospital admission or hospital discharge. The authors concluded that ACD CPR does not provide significant benefits over standard CPR. ${ }^{16}$ Another meta-analysis by Wang et al. suggested that the ACD CPR device is difficult to adhere to the patient's chest during resuscitation. ${ }^{17}$

\section{Addition of the impedance threshold device}

During a 1994 trial evaluating standard and ACD CPR, the investigators observed that temporary occlusion of the endotracheal tube in one patient during standard CPR produced a more negative intrathoracic pressure 
than obtained with ACD CPR during active decompression. ${ }^{18}$ These results led to the testing of an impedance threshold device (ITD) called the ResQPod ${ }^{\mathbb{R}}$ (Zoll Medical Corp., Chelmsford, MA, USA) along with the ResQPump $^{\circledR}$ (Zoll Medical Corp., Chelmsford, MA, USA), to augment the benefits of ACD CPR. ${ }^{19}$ The $\operatorname{ResQPod}^{\circledR}$ (Zoll Medical Corp., Chelmsford, MA, USA) can attach to a facemask or endotracheal tube (Figure 2). An ITD is used during basic and advanced life support as part of the airway, preventing inspiration during the CPR decompression phase. The upward movement of the thoracic wall during this phase leads to a drop in intrathoracic pressure. By preventing air influx, the ITD permits a greater negative pressure to build, allowing for greater cardiac and cerebral perfusion with ACD CPR alone. ${ }^{6,20-22}$

In 2011, the randomized ResQTrial study encompassing 46 emergency medical service agencies was published in The Lancet. This study examined the differences between standard CPR and ACD plus ITD CPR (using the $\operatorname{ResQPump}^{\circledR}$ (Figure 1C) with the $\operatorname{ResQPod}^{\circledR}$ (Figure 2); Zoll Medical Corp., Chelmsford, MA, USA) or patients with a suspected non-traumatic out-of-hospital cardiac

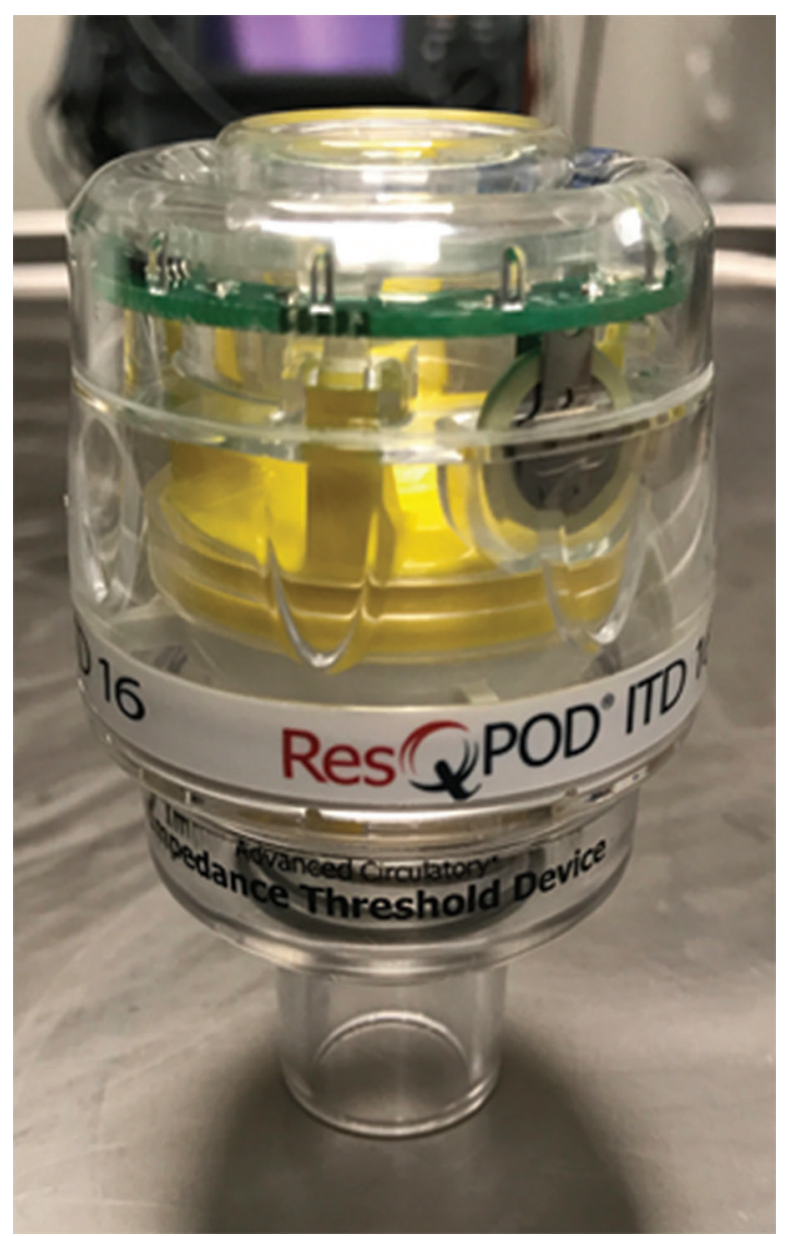

Figure 2: The impedance threshold device known as the ResQPod ${ }^{\mathbb{R}}$, initially manufactured by Advanced Circulatory Systems Inc. (Roseville, MN, USA), and now manufactured by Zoll Medical Corp. (Chelmsford, MA, USA). arrest due to cardiac causes. ${ }^{6}$ The use of an ACD plus ITD CPR device, known as the ResQCPR ${ }^{\mathrm{TM}}$ system (Zoll Medical Corp., Chelmsford, MA, USA) yielded statistically significant increases in survival to hospital discharge and one-year survival rate over standard CPR. Although the intervention group had an increased incidence of pulmonary edema, there was almost no difference in post-cardiac arrest neurological function in the intervention group versus in the control (standard (PR) group. Relative survival to hospital discharge and one-year survival increased by almost $50 \%$ when using ACD plus ITD CPR. This study became the foundation for the FDA's approval of the ResQCPR ${ }^{\mathrm{TM}}$ system (Zoll Medical Corp., Chelmsford, MA, USA) in March 2015. ${ }^{23}$ At the time, the original manufacturer of both the ResQPod ${ }^{\circledR}$ and ResQPump ${ }^{\circledR}$, Advanced Circulatory Systems Inc. (Roseville, MN, USA), was acquired by Zoll Medical Corp. (Chelmsford, MA, USA), bringing these two devices under the latter company's umbrella.

Following completion of the ResQTrial, Frascone et al. assessed whether ACD plus ITD CPR would improve survival following cardiac arrest independent of the out-of-hospital non-traumatic etiology. They found a $38 \%$ increase in survival to hospital discharge with favorable neurologic outcomes, and a 39\% relative increase in one-year survival following cardiac arrest for ACD plus ITD CPR, independent of the cause of cardiac arrest. ${ }^{24}$ A 2015 review concluded that compared with standard CPR, ACD plus ITD CPR achieved increased blood flow and associated patient survival rates for out-of-hospital cardiac arrest regardless of etiology. ${ }^{7}$

\section{Mechanical ACD devices}

A mechanical version of the ACD device was created and termed the Lund University Cardiopulmonary Assist System (LUCAS ${ }^{\circledR}$ ) (Figure 3). This gas-driven device provides mechanical compression and active decompression. ${ }^{25,26}$ It is composed of a silicone rubber suction cup with a pneumatic cylinder on a handle connected to a back plate. The LUCAS ${ }^{\mathbb{R}}$ allows for more uniform chest compressions compared with conventional CPR. ${ }^{27}$ The machine provides uninterrupted, high-quality chest compressions without human fatigue. Because the LUCAS ${ }^{\circledR}$ does not require medical technicians to utilize their hands to perform chest compressions, these individuals can sit properly strapped into the moving vehicle or focus on performing other lifesaving tasks, including starting an intravenous line, placing an advanced airway, and contacting the hospital to provide updates on the patient's condition. ${ }^{27}$ The LUCAS ${ }^{\circledR}$ is now in its third generation as the LUCAS ${ }^{\circledR} 3$ (Physio-Control, Inc., Redmond, WA), which offers improved maintenance and handling, as well as the new feature of wireless access to data collected by the device. ${ }^{28}$

\section{CPR guidelines}

ACD CPR was described in the 2015 CPR and emergency cardiovascular care guidelines as an alternative technique 


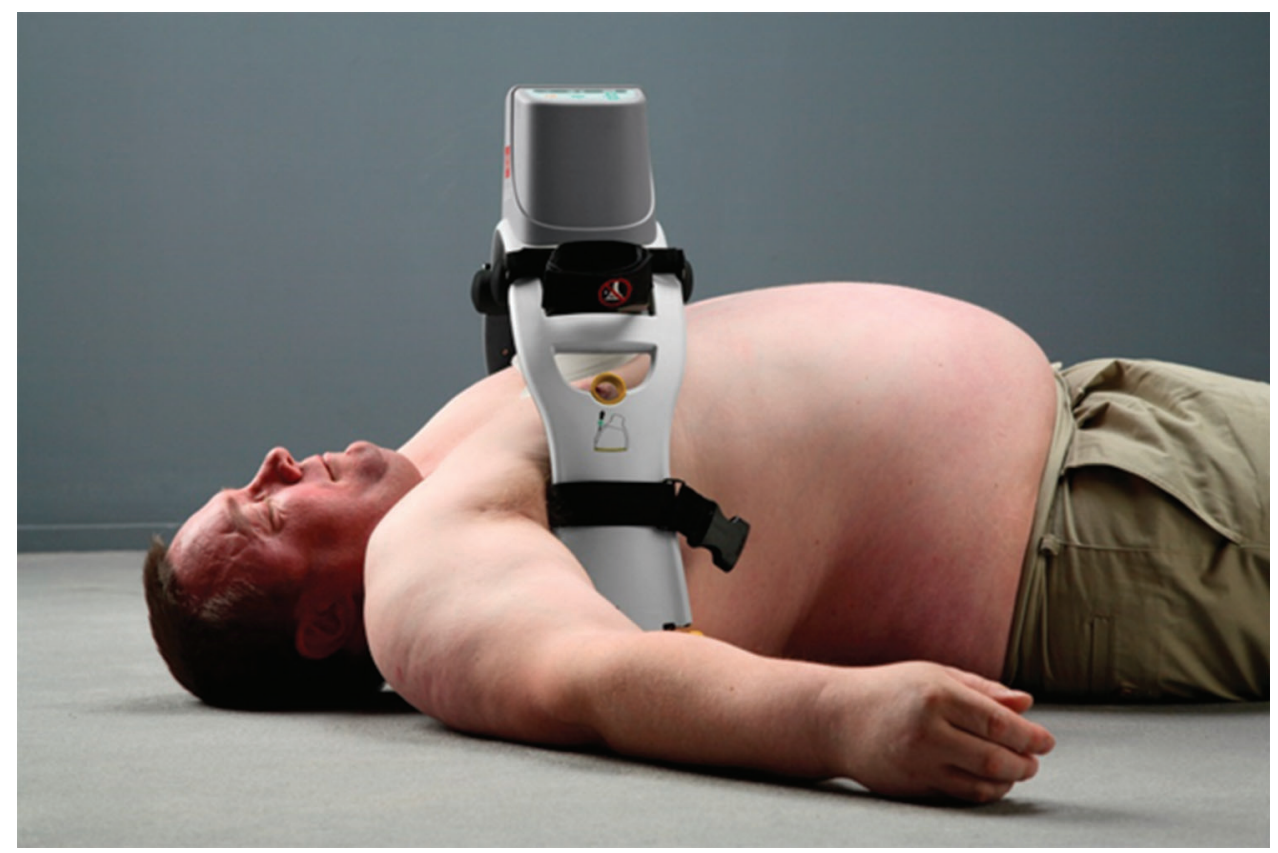

Figure 3: The LUCAS ${ }^{\circledR} 3$ (Physio-Control, Inc., Redmond, WA), a mechanical ACD CPR device. Photo courtesy of Physio-Control, Inc. ACD: active compression-decompression; CPR: cardiopulmonary resuscitation.

to standard CPR, but the results of its use were mixed. ${ }^{29}$ Multiple studies have shown that ACD CPR increases short-term survival, ROSC, and neurological intactness as compared with standard CPR. 12,15,30-33 Conversely, other investigations reported no difference in ROSC or survival associated with the use of ACD CPR. ${ }^{34-40}$ Due to the current lack of consensus, the guidelines do not officially recommend for or against ACD CPR use, but do note that the technique can be considered if the user is trained or supervised by trained professionals while using the device. ${ }^{29}$

The guidelines also discuss the use of ACD plus ITD CPR and mention studies with varied results. Some found no difference in survival to discharge between ACD CPR with or without the ITD. ${ }^{21,22,41}$ One trial comparing conventional CPR and ACD plus ITD CPR found increased one-year survival following cardiac arrest with ACD plus ITD CPR use. ${ }^{8,24}$ Due to a lack of research on this method, however, it is not a recommended alternative for conventional CPR unless performed by trained personnel. ${ }^{29}$

Mechanical chest compression piston devices are also mentioned in the guidelines. Two studies conducted using the LUCAS ${ }^{\mathbb{R}}$ and three studies that tested other mechanical chest compression devices, respectively, found no difference in patient survival when comparing the use of mechanical and manual chest compression techniques. ${ }^{42-46}$ One other trial using the LUCAS $^{\circledR}$ reported a negative correlation between mechanical ACD CPR and survival with favorable neurologic outcomes. ${ }^{47}$ The guidelines state that the use of mechanical piston devices is a comparable method to the performance of manual CPR when performed by properly trained individuals. ${ }^{29}$ Such devices

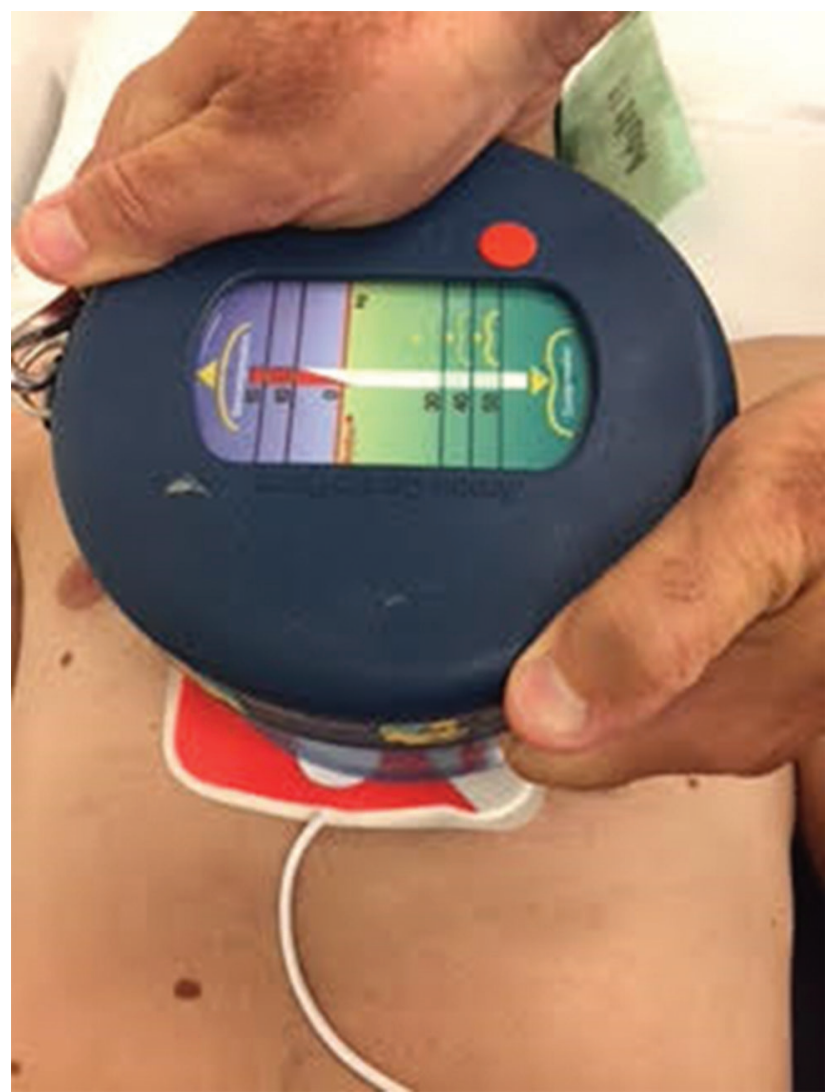

Figure 4: An example of $A C D^{2}$, in which a defibrillation patch is placed under the ACD CPR device.

may enable staff to assist in other aspects of advanced cardiac life support. 


\section{A handheld active compression device to augment external cardioversion and defibrillation}

In 1995, a study described a new technique called ACD defibrillation $\left(\mathrm{ACD}^{2}\right)$, in which a defibrillation skin patch was placed inside the suction cup of an ACD device (Figure 4). By placing the defibrillation pad underneath the device, defibrillation was delivered to the patient during the downstroke of chest compressions during continuous $\mathrm{CPR}$. $\mathrm{ACD}^{2}$ was tested on seven canines with induced ventricular fibrillation, yielding a significant reduction in transthoracic impedance as compared with the standard CPR technique. Notably, reduced transthoracic impedance may increase defibrillation efficacy. Although not statistically significant, improvements in defibrillation thresholds were noted. ${ }^{48}$ In 1996 , Cohen et al. tested this technique on humans. Standard cardioversion was first attempted in 22 patients with atrial fibrillation; if it failed, active compression cardioversion was used. Four of the five patients who failed initial standard cardioversion were converted to sinus rhythm using active compression cardioversion.
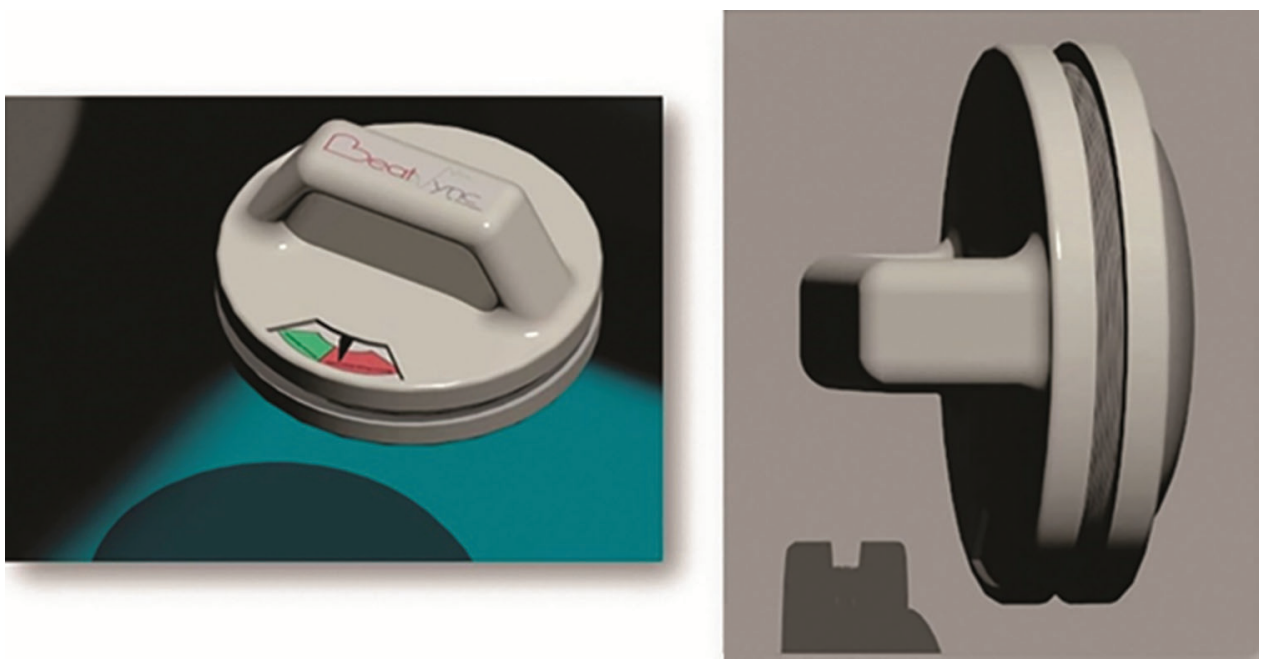

Figure 5: The PrestoPush ${ }^{\mathrm{TM}}$ (Nexus Control Systems LLC, Port Washington, NY, USA) is a handheld device designed to improve the efficacy of external cardioversion and defibrillation. Image reprinted with permission from: Cohen TC, eds. Practical Electrophysiology. 3rd ed. Malvern, PA: HMP Communications; 2016: 17-171.

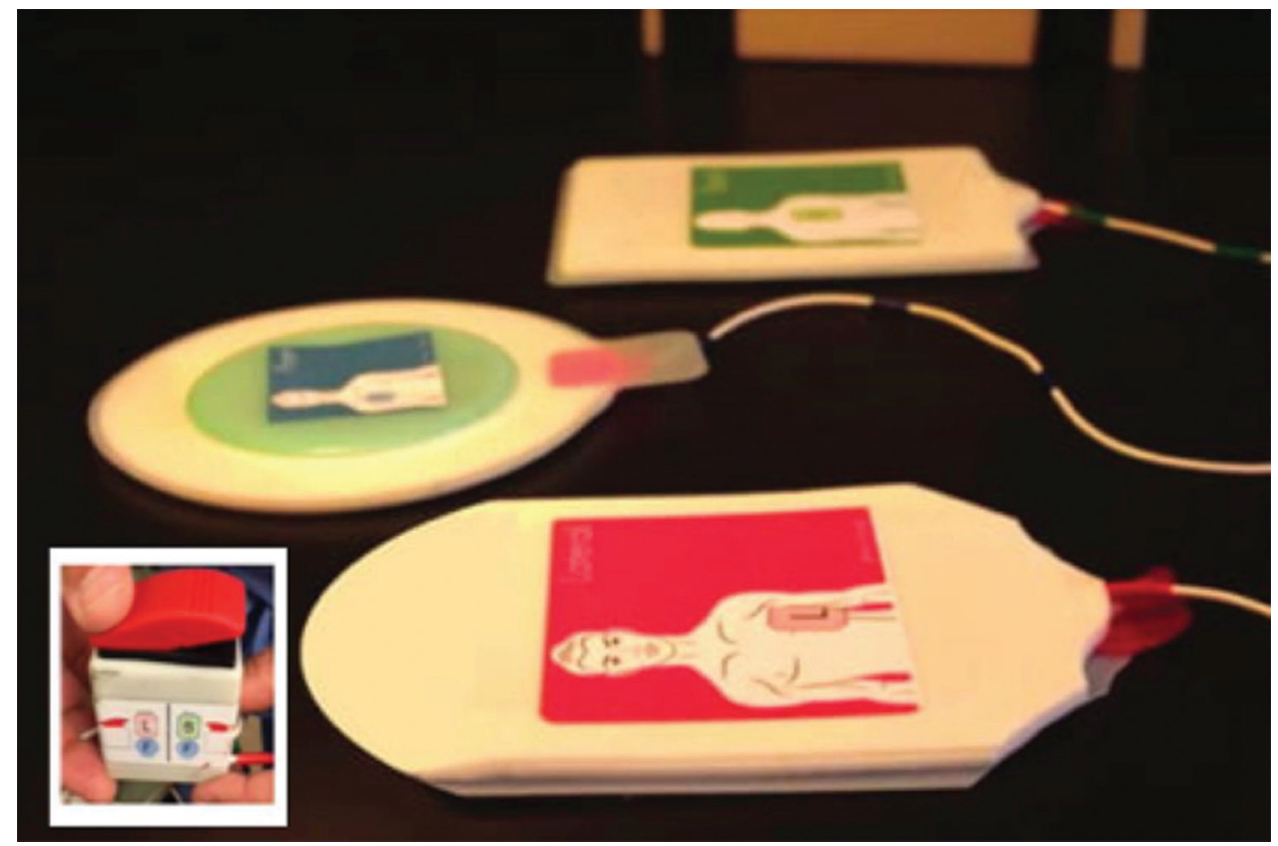

Figure 6: The PrestoPatch ${ }^{\mathrm{TM}}$ (Nexus Control Systems LLC, Port Washington, NY, USA) consists of an arrangement of three defibrillation patches and a high-voltage switch. Large image reprinted with permission from: Cohen TC, eds. Practical Electrophysiology. 3rd ed. Malvern, PA: HMP Communications; 2016: 17-171. The lower left corner insert shows the switch box, which connects to the three-patch system to provide shocks. Insert image added courtesy of Nexus Control Systems, LLC. 
Table 1: Selected studies of ACD CPR

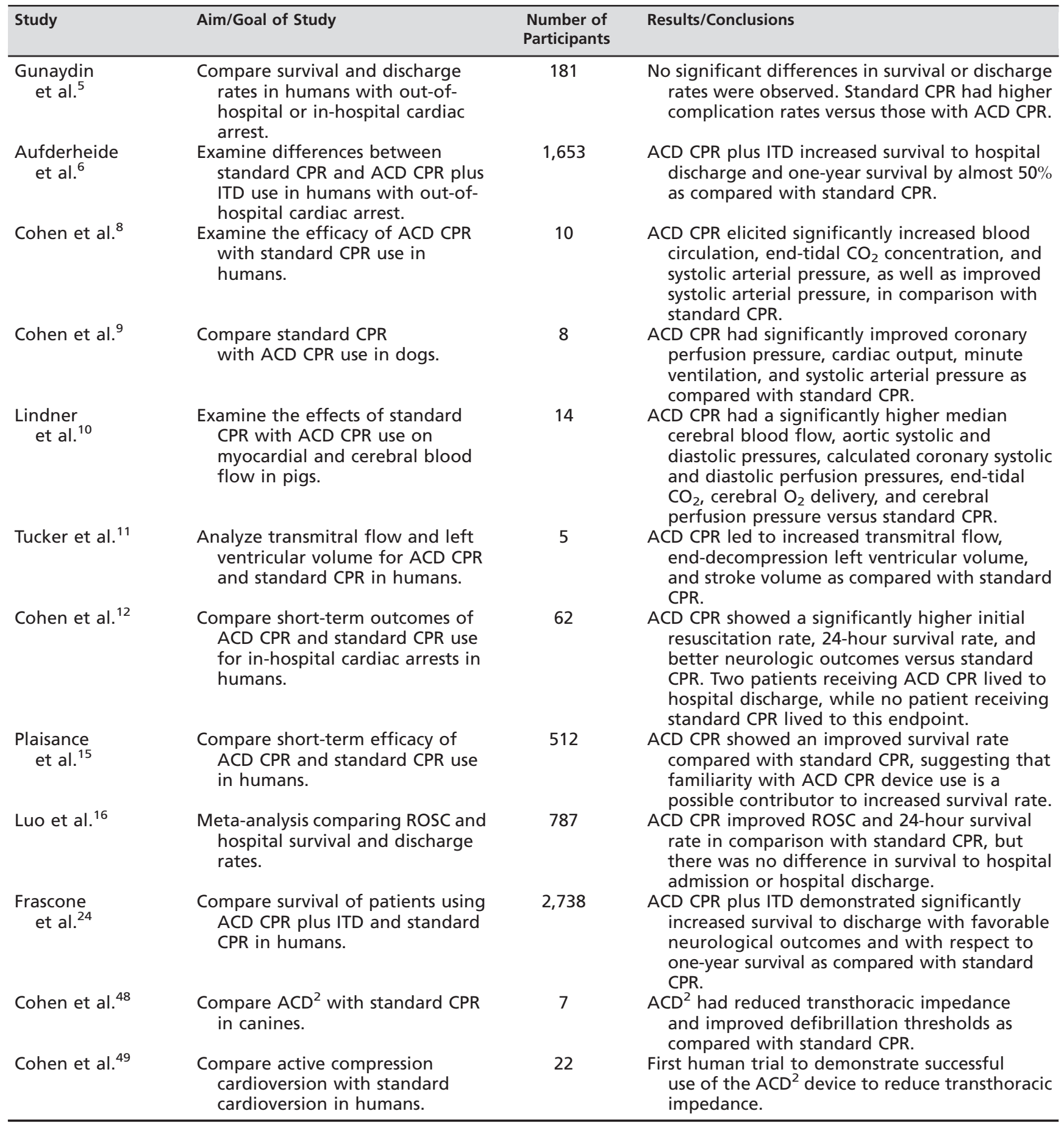

Abbreviations: $\mathrm{ACD}$ : active compression-decompression; $\mathrm{ACD}^{2}$ : active compression-decompression defibrillation; $\mathrm{CO}_{2}$ : carbon dioxide; CPR: cardiopulmonary resuscitation; ITD: impedance threshold device; $\mathrm{O}_{2}$ : oxygen; ROSC: restoration of spontaneous circulation.

This study was the first human trial to demonstrate the successful use of a simple, handheld, insulated device capable of applying calibrated pressures over a cardioversion/defibrillation patch to reduce transthoracic impedance. $^{49}$

In 2013, a team of biomedical engineering students from Johns Hopkins University led and supported by
Dr. Cohen adapted $\mathrm{ACD}^{2}$ principles to a handheld insulated device called the PrestoPush ${ }^{\mathrm{TM}}$ (Nexus Control Systems LLC, Port Washington, NY, USA) (Figure 5). This custom-designed, handheld insulated device containing a gauge to control and guide the force applied to the chest was created to improve external cardioversion and defibrillation. This device may increase the effectiveness of external cardioversion and defibrillation by decreasing the 
intrathoracic impedance, which is useful in patients who are clinically obese. ${ }^{2}$ The same team also developed a vector-switching device called the PrestoPatch ${ }^{\mathrm{TM}}$ (Nexus Control Systems LLC, Port Washington, NY, USA) (Figure 6). This device consists of three defibrillator patches, along with a high-voltage switch used to alter the shocking vector without moving the patches. In 2013, the Johns Hopkins University team won the National Collegiate Inventors Competition for the PrestoPatch ${ }^{\mathrm{TM}}$ and PrestoPush ${ }^{\mathrm{TM}}$ (both Nexus Control Systems LLC, Port Washington, NY, USA).

\section{Conclusions}

Over time, ACD CPR has evolved from its original concept as a handheld plunger appliance to the more sophisticated ResQPump ${ }^{\circledR}$ CPR device (Zoll Medical Corp., Chelmsford, MA, USA) and the LUCAS ${ }^{\circledR}$ mechanical version. Selected studies highlighted in Table 1 illustrate this transformation. Adjuncts such as the PrestoPatch ${ }^{\mathrm{TM}}$ and PrestoPush ${ }^{\mathrm{TM}}$ assistive devices (both Nexus Control Systems LLC, Port Washington, NY, USA) have also been introduced. Despite these significant advances, there are still no strong recommendations for the use of these tools in current CPR guidelines, though they may be considered in scenarios in which providers are adequately trained and monitored in their use. These innovative products are derivatives of active compression and decompression concepts applied to the cardiovascular system. Future methods and devices may potentially be applied to other regions of the body to augment medical treatments.

\section{References}

1. Go AS, Mozaffarian D, Roger VL, et al. Heart disease and stroke statistics-2013 update: a report from the American Heart Association. Circulation. 2013;127(1):e6-e245.

2. Beinborn DS. Basic, advanced, and pediatric cardiac life support: being prepared for emergencies in the electrophysiology lab. In: Cohen TJ, ed. Practical Electrophysiology. 3rd ed. Malvern, PA: HMP Communications; 2016: 27-40.

3. Lurie KG, Lindo C, Chin J. CPR: the P stands for plumber's helper. JAMA. 1990;264(13):1661.

4. Metzger AK, Herman M, McKnite S, Tang W, Yannopoulos D. Improved cerebral perfusion pressures and 24-hr neurological survival in a porcine model of cardiac arrest with active compression-decompression cardiopulmonary resuscitation and augmentation of negative intrathoracic pressure. Crit Care Med. 2012;40(6):1851-1856.

5. Günaydın YK, Çekmen B, Akıllı NB, Köylü R, Sert ET, Cander B. Comparative effectiveness of standard CPR vs active compression-decompression CPR with CardioPump for treatment of cardiac arrest. Am J Emerg Med. 2016;34(3): 542-547.

6. Aufderheide TP, Frascone RJ, Wayne MA, et al. Standard cardiopulmonary resuscitation versus active compressiondecompression cardiopulmonary resuscitation with augmentation of negative intrathoracic pressure for out-of-hospital cardiac arrest: a randomised trial. Lancet. 2011;377(9762): 301-311.

7. Chen SQ. Advances in clinical studies of cardiopulmonary resuscitation. World J Emerg Med. 2015;6(2):85-93.
8. Cohen TJ, Tucker KJ, Lurie KG, et al. Active compressiondecompression. A new method of cardiopulmonary resuscitation. Cardiopulmonary Resuscitation Working Group. JAMA. 1992;267(21):2916-2923.

9. Cohen TJ, Tucker KJ, Redberg RF, et al. Active compressiondecompression resuscitation: a novel method of cardiopulmonary resuscitation. Am Heart J. 1992;124(5):1145-1150.

10. Lindner KH, Pfenninger EG, Lurie KG, Schürmann W, Lindner IM, Ahnefeld FW. Effects of active compressiondecompression resuscitation on myocardial and cerebral blood flow in pigs. Circulation. 1993;88(3):1254-1263.

11. Tucker KJ, Redberg RF, Schiller NB, Cohen TJ. Active compression-decompression resuscitation: analysis of transmitral flow and left ventricular volume by transesophageal echocardiography in humans. Cardiopulmonary Resuscitation Working Group. J Am Coll Cardiol. 1993;22(5): 1485-1493.

12. Cohen TJ, Goldner BG, Maccaro PC, et al. A comparison of active compression-decompression cardiopulmonary resuscitation with standard cardiopulmonary resuscitation for cardiac arrests occurring in the hospital. N Engl J Med. 1993; 329(26):1918-1921.

13. Shultz JJ, Schwab T, Callaham M, et al. Active compressiondecompression CPR improves prehospital cardiopulmonary arrest survival. Abstract. Pacing Clin Electrophysiol. 1993; 16(Part II):928.

14. Mauer DK, Nolan J, Plaisance $P$, et al. Effect of active compression-decompression resuscitation (ACD-CPR) on survival: a combined analysis using individual patient data. Resuscitation. 1999;41(3):249-256.

15. Plaisance P, Adnet F, Vicaut E, et al. Benefit of active compression-decompression cardiopulmonary resuscitation as a prehospital advanced cardiac life support. A randomized multicenter study. Circulation. 1997;95(4):955-961.

16. Luo XR, Zhang HL, Chen GJ, Ding WS, Huang L. Active compression-decompression cardiopulmonary resuscitation (CPR) versus standard CPR for cardiac arrest patients: a metaanalysis. World J Emerg Med. 2013;4(4):266-272.

17. Wang CH, Tsai MS, Chang WT, et al. Active compressiondecompression resuscitation and impedance threshold device for out-of-hospital cardiac arrest: a systematic review and metaanalysis of randomized controlled trials. Crit Care Med. 2015;43(4):889-896.

18. Shultz JJ, Coffeen P, Sweeney M, et al. Evaluation of standard and active compression-decompression CPR in an acute human model of ventricular fibrillation. Circulation. 1994;89(2):684-693.

19. Lurie KG, Coffeen P, Shultz J, McKnite S, Detloff B, Mulligan K. Improving active compression-decompression cardiopulmonary resuscitation with an inspiratory impedance valve. Circulation. 1995;91(6):1629-1632.

20. Plaisance P, Soleil C, Lurie KG, Vicaut E, Ducros L, Payen D. Use of an inspiratory impedance threshold device on a facemask and endotracheal tube to reduce intrathoracic pressures during the decompression phase of active compression-decompression cardiopulmonary resuscitation. Crit Care Med. 2005;33(5):990-994.

21. Plaisance $P$, Lurie KG, Payen D. Inspiratory impedance during active compression-decompression cardiopulmonary resuscitation: a randomized evaluation in patients in cardiac arrest. Circulation. 2000;101(9):989-994.

22. Wolcke BB, Mauer DK, Schoefmann MF, et al. Comparison of standard cardiopulmonary resuscitation versus the combination of active compression-decompression cardiopulmonary resuscitation and an inspiratory impedance threshold device for out-of-hospital cardiac arrest. Circulation. 2003;108(18):2201-2205. 
23. US Food and Drug Administration. ResQCPR System: ResQPump (ACD-CPR device) and ResQPOD ITD 16-P110024. Available at: https://www.fda.gov/MedicalDevices/Pro ductsandMedicalProcedures / DeviceApprovalsandClear ances/Recently-ApprovedDevices/ucm439088.htm. Accessed July 25, 2017.

24. Frascone RJ, Wayne MA, Swor RA, et al. Treatment of nontraumatic out-of-hospital cardiac arrest with active compression decompression cardiopulmonary resuscitation plus an impedance threshold device. Resuscitation. 2013; 84(9):1214-1222.

25. Steen S, Sjöberg T, Olsson P, Young M. Treatment of outof-hospital cardiac arrest with LUCAS, a new device for automatic mechanical compression and active decompression resuscitation. Resuscitation. 2005;67(1):25-30.

26. Steen S, Liao Q, Pierre L, Paskevicius A, Sjöberg T. Evaluation of LUCAS, a new device for automatic mechanical compression and active decompression resuscitation. Resuscitation. 2002;55(3):285-299.

27. Gyory RA, Buchle SE, Rodgers D, Lubin JS. The efficacy of LUCAS in prehospital cardiac arrest scenarios: a crossover mannequin study. West J Emerg Med. 2017;18(3): 437-445.

28. Physio-Control. LUCAS 3 Chest Compression System. Available at: http://www.physio-control.com/WCProductDetails. aspx?id=2147484788. Accessed July 25, 2017.

29. American Heart Association. Part 6: Alternative Techniques and Ancillary Devices for Cardiopulmonary Resuscitation. ECC Guidelines 2015. Available at: https://eccguidelines. heart.org /index.php/circulation/cpr-ecc-guidelines-2/part6-alternative-techniques-and-ancillary-devices-for-cardi opulmonary-resuscitation $/$ ?strue $=1 \&$ id $=4-2-4-1$. Accessed July 25, 2017.

30. Lurie KG, Shultz JJ, Callaham ML, et al. Evaluation of active compression-decompression CPR in victims of out-ofhospital cardiac arrest. JAMA. 1994;271(18):1405-1411.

31. Tucker KJ, Galli F, Savitt MA, Kahsai D, Bresnahan L, Redberg RF. Active compression-decompression resuscitation: effect on resuscitation success after in-hospital cardiac arrest. J Am Coll Cardiol. 1994;24(1):201-209.

32. Plaisance P, Lurie KG, Vicaut E, et al. A comparison of standard cardiopulmonary resuscitation and active compressiondecompression resuscitation for out-of-hospital cardiac arrest. French Active Compression-Decompression Cardiopulmonary Resuscitation Study Group. N Engl J Med. 1999;341(8): 569-575.

33. He Q, Wan Z, Wang L. [Random control trial of the efficacy of cardiopump on pre-hospital cardiac arrest]. Zhongguo Wei Zhong Bing Ji Jiu Yi Xue. 2003;15:292-294. Chinese.

34. Mauer D, Schneider T, Dick W, Withelm A, Elich D, Mauer $\mathrm{M}$. Active compression-decompression resuscitation: a prospective, randomized study in a two-tiered EMS system with physicians in the field. Resuscitation. 1996;33(2):125-134.

35. Stiell IG, Hebert PC, Wells GA, et al. The Ontario trial of active compression-decompression cardiopulmonary resuscitation for in-hospital and prehospital cardiac arrest. JAMA. 1996;275(18):1417-1423.
36. Goralski M, Villeger JL, Cami G, et al. [Evaluation of active compression-decompression cardiopulmonary resuscitation in out-of-hospital cardiac arrest]. Reanimation Urgences. 1998; 7(5):543-550.

37. Skogvoll E, Wik L. Active compression-decompression cardiopulmonary resuscitation: a population-based, prospective randomised clinical trial in out-of-hospital cardiac arrest. Resuscitation. 1999;42(3):163-172.

38. Schwab TM, Callaham ML, Madsen CD, Utecht TA. A randomized clinical trial of active compression-decompression CPR vs standard CPR in out-of-hospital cardiac arrest in two cities. JAMA. 1995;273(16):1261-1268.

39. Luiz T, Ellinger K, Denz C. Active compression-decompression cardiopulmonary resuscitation does not improve survival in patients with prehospital cardiac arrest in a physician-manned emergency medical system. J Cardiothorac Vasc Anesth. 1996; 10(2):178-186.

40. Nolan J, Smith G, Evans R, et al. The United Kingdom prehospital study of active compression-decompression resuscitation. Resuscitation. 1998;37(2):119-125.

41. Plaisance $P$, Lurie KG, Vicaut E, et al. Evaluation of an impedance threshold device in patients receiving active compression-decompression cardiopulmonary resuscitation for out of hospital cardiac arrest. Resuscitation. 2004;61(3): 265-271.

42. Smekal D, Johansson J, Huzevka T, Rubertsson S. A pilot study of mechanical chest compressions with the LUCAS ${ }^{\mathrm{TM}}$ device in cardiopulmonary resuscitation. Resuscitation. 2011; 82(6):702-706

43. Rubertsson S, Lindgren E, Smekal D, et al. Mechanical chest compressions and simultaneous defibrillation vs conventional cardiopulmonary resuscitation in out-of-hospital cardiac arrest: the LINC randomized trial. JAMA. 2014;311(1): 53-61.

44. Taylor GJ, Rubin R, Tucker M, Greene HL, Rudikoff MT, Weisfeldt ML. External cardiac compression. A randomized comparison of mechanical and manual techniques. JAMA. 1978;240(7):644-646.

45. Ward KR, Menegazzi JJ, Zelenak RR, Sullivan RJ, McSwain NE Jr. A comparison of chest compressions between mechanical and manual CPR by monitoring end-tidal PCO2 during human cardiac arrest. Ann Emerg Med. 1993;22(4):669-674.

46. Dickinson ET, Verdile VP, Schneider RM, Salluzzo RF. Effectiveness of mechanical versus manual chest compressions in out-of-hospital cardiac arrest resuscitation: a pilot study. Am J Emerg Med. 1998;16(3):289-292.

47. Perkins GD, Lall R, Quinn T, et al. Mechanical versus manual chest compression for out-of-hospital cardiac arrest (PARAMEDIC): a pragmatic, cluster randomised controlled trial. Lancet. 2015;385(9972):947-955.

48. Cohen TJ, Noubani H, Goldner BG, et al. Active compression-decompression defibrillation provides effective defibrillation during cardiopulmonary resuscitation. Am Heart J. 1995;130(1):186-187.

49. Cohen TJ, Ibrahim B, Denier D, Haji A, Quan W. Active compression cardioversion for refractory atrial fibrillation. Am J Cardiol. 1997;80(3):354-355. 